\title{
Genome-wide microRNA changes in human intracranial aneurysms
}

\author{
Dehua Liu ${ }^{1 \dagger}$, Liang Han ${ }^{1 \dagger}$, Xiao $\mathrm{Wu}^{2}$, Xinjian Yang ${ }^{3}$, Qunye Zhang ${ }^{2^{*}}$ and Fan Jiang ${ }^{2^{*}}$
}

\begin{abstract}
Background: Intracranial aneurysms are pathological dilatations of the cerebral artery, while rupture of intracranial aneurysms causes life-threatening subarachnoid hemorrhage. The molecular mechanisms of pathogenesis of intracranial aneurysms are poorly understood. MicroRNAs have fundamental roles in modulating vascular biology and disease. In the present study, we carried out a genome-wide characterization on expressions of microRNAs, and performed integrative analyses in conjunction with changes of the transcriptome in human intracranial aneurysms.
\end{abstract}

Methods: Genome-wide microRNA screening was performed in 6 intracranial aneurysmal samples and 6 normal superficial temporal arteries. Each case and control pair was individually matched with gender, age ( \pm 5 years), and high blood pressure history. Microarray analysis was performed using Agilent Human miRNA arrays.

Results: As compared to normal arteries, we identified 157 microRNAs that were differentially expressed in the aneurysmal tissue $(P<0.05$ and fold change $\geq 2$ ), including 72 upregulated and 85 downregulated. The changed microRNAs included endothelium-enriched microRNAs such as members of the let-7 family, miR-17, miR-23b, miR-126, hsa-miR-24-1 and miR-222, and vascular smooth muscle-enriched miRNAs such as miR-143 and miR-145. Moreover, miR-1, miR-10a, miR-125b, and miR-26a, which were implicated in modulating vascular smooth muscle cell functions such as proliferation, apoptosis and shift of phenotype, were also changed. In contrast, microRNAs involved in monocyte and macrophage functions, such as miR-155, miR-146a, miR-223, and miR-124a, were not significantly changed. Bioinformatic analysis revealed that the changed microRNAs were associated with several biological processes related to aneurysm formation, including inflammation, dysregulation of extracellular matrix, smooth muscle cell proliferation, programmed cell death, and response to oxidative stress. Interestingly, we found that a subset of the potential microRNA target genes belonged to the protein translation machinery, including various eukaryotic translation initiation factors and ribosomal proteins, and this finding was highly correlated with our previous transcriptome data showing that multiple genes of the ribosomal proteins and translation initiation and elongation factors were significantly downregulated in human intracranial aneurysms.

Conclusions: Our results support that dysregulated microRNAs may have a pathogenic role in intracranial aneurysms. Disruption of the protein translation process may have a pathogenic role in the development of intracranial aneurysms.

Keywords: Intracranial aneurysm, microRNA, Microarray, Human, Cerebral vascular disease, System biology, Transcriptome, Protein translation machinery

\footnotetext{
*Correspondence: maogou1974@gmail.com; fjiang@sdu.edu.cn

${ }^{\dagger}$ Equal contributors

${ }^{2}$ Key Laboratory of Cardiovascular Remodeling and Function Research, Qilu

Hospital, 107 Wenhuaxi Road, Jinan 250012, Shandong Province, China

Full list of author information is available at the end of the article
} 


\section{Background}

Intracranial aneurysms (IAs) are pathological dilatations of the cerebral artery; rupture of IAs is the primary cause of life-threatening subarachnoid hemorrhage (SAH) [1-3]. The cellular and molecular mechanisms underlying the pathogenesis of IA formation are still poorly understood. Factors including smoking, hypertension, excessive alcohol consumption, vascular inflammation, nutritional factors and mechanical forces produced by the blood flow may all contribute to the formation and/or rupture of IAs [4-10]. On the other hand, mounting evidence has suggested that genetic factors (such as gene polymorphisms) also have important roles in the etiology of IAs $[11,12]$.

Throughout IA research, identification of aberrantly expressed genes in IA tissues remains to be a core approach to understanding the molecular regulatory mechanisms underlying IA development and rupture. In line with this, several groups have employed high-throughput microarray methods to study gene expression changes at the whole genome level [13-17]. For example, in a previous study, we identified 1,160 genes whose expression levels were significantly changed in un-ruptured aneurysmal tissues as compared to normal blood vessels [15]. We found that a cluster of extracellular matrix related genes (including collagens type I, III, V, and XI and metalloproteinases) were significantly changed. Moreover, we found that a number of immune/inflammation-related genes were also differentially expressed in IA tissues [15]. Collectively, these functional genomic studies provided important information regarding the potential molecular mechanisms implicated in this multifactorial cerebral vascular disease [18].

MicroRNAs (miRNAs) are a class of short (18-25 nucleotides), non-coding RNAs that have fundamental roles in post-transcriptional regulation of gene expression. Regulation of gene expression by miRNAs may be achieved via either sequence-specific interactions with target mRNAs and subsequent mRNA degradation, or miRNA-mediated translational repression $[19,20]$. Therefore, miRNAs represent another layer of regulation of gene expression in addition to the conventional promoter-dependent transcriptional regulation. There is evidence showing that miRNAs are able to regulate a variety of target genes which are critical for the homeostasis of vascular endothelial and smooth muscle cells [21]. Consistent with this notion, experimental studies have revealed that aberrant expression of several miRNAs may be involved in pathological vascular remodeling, in which each individual miRNA may have a specific protective or pathogenic role [22,23]. In particular, different groups have shown that the expression levels of many miRNAs are significantly changed in human abdominal aortic aneurysm (AAA) tissues [24,25].

Currently, however, there is limited information about alterations in miRNA expression in cerebral aneurysms. A recent genomic study demonstrated that in human IA tissues, 18 miRNAs were significantly downregulated [26]. Despite these pilot results, however, there is evidence suggesting that the degree of correlation between different microarray data sets is low [18]. Hence, given the small sample number included in the previous study, a necessity for separate verification experiments is highlighted. In our previous study, we demonstrated that a subset of inflammation-related miRNAs were selectively upregulated in the plasma of stroke patients with intracerebral hemorrhage [27]. In the present study, we carried out experiments to detect genomewide changes in miRNA expression in IAs, and performed integrative analyses in conjunction with changes of the IA transcriptome, in an attempt to identify novel biological processes that might be implicated in IA pathogenesis.

\section{Methods}

\section{Patient recruitment}

This study was approved (\#10051) by the Human Ethics Committee of Shandong University Qilu Hospital, and informed consents were obtained before start of the experiment, directly from the patients or their first-degree relatives of unconscious subjects. Six patients with IAs undergoing surgical clipping treatment were included in the study. These cases were selected by the operating neurosurgeons on a basis that removal of the residual aneurysmal wall would not affect the outcome of the treatment. IA tissues were removed during clipping surgery (see Figure 1) and snap-frozen in liquid nitrogen. The basic clinical data of patients and characteristics of the aneurysms were summarized in Table 1 . Normal superficial temporal arteries were collected from traumatic patients undergoing craniotomy treatments. Each case was individually matched in gender, age ( \pm 5 years), and high blood pressure history

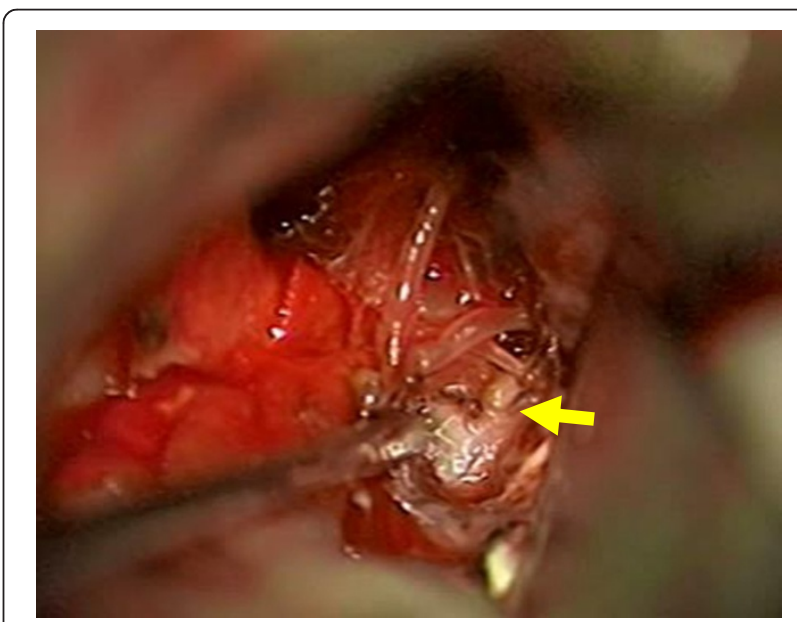

Figure 1 A photo taken during surgery showing the gross pathology of an aneurysm (arrow) of the posterior communication artery. 
Table 1 Clinical profiles of patients included in the microarray study and characteristics of the aneurysms

\begin{tabular}{|c|c|c|c|c|c|c|c|c|}
\hline Sample \# & Gender & Age range & Hypertension & Smoking history & Family history & Site of aneurysm & Type of aneurysm & Ruptured \\
\hline $1^{*}$ & $\mathrm{~F}$ & $60-65$ & Y & $\mathrm{Y}$ & N & Right internal carotid-posterior communicating artery & $\|$ & Y \\
\hline $2^{*}$ & $\mathrm{~F}$ & $55-60$ & Y & N & N & Posterior communicating artery & $\|$ & Y \\
\hline 3 & M & $45-50$ & $\mathrm{~N}$ & Y & N & Left middle cerebral artery-M2 segment & $\|$ & Y \\
\hline $4^{*}$ & $\mathrm{~F}$ & $50-55$ & N & N & N & Left anterior cerebral artery & $\|$ & Y \\
\hline $5^{*}$ & $\mathrm{~F}$ & $50-55$ & N & N & N & Left anterior cerebral artery-A2 segment & III & Y \\
\hline 6 & $\mathrm{~F}$ & $45-50$ & N & $\mathrm{N}$ & $\mathrm{N}$ & Right posterior communicating artery & $\|$ & Y \\
\hline
\end{tabular}

*Samples \#1 \& \#2 were combined before the microarray test because the yield of total RNA from each single sample was not enough for microarray detection. Samples \#4 \& \#5 were also combined. 
with controls. All of the control subjects were free of family history of aneurysmal disorders.

\section{Sample processing and RNA extraction}

Frozen tissues were quickly transferred into TRIzol Reagent (Life Technologies, Grand Island, NY, USA) and homogenized immediately with a Dounce tissue grinder. Total RNA was isolated according to the manufacturer's protocol and analyzed with Agilent Bioanalyzer 2100 (Agilent, Santa Clara, CA, USA). Because the total RNA yield from some aneurysmal tissues was below the minimum amount required for routine microarray detection, these low-yield samples were then combined to increase the mass of total RNA (see Table 1 footnote).

\section{Microarray assays}

Microarray analysis was performed using Agilent Human miRNA (8*15K) V14.0 arrays (design ID: 31945) at ShanghaiBio Corporation (Shanghai, China). The miRNA molecules were labeled using the miRNA Complete Labeling and Hyb Kit from Agilent, following the manufacturer's standard protocol. Each slide was hybridized with $100 \mathrm{ng}$ Cy3-labeled RNA in hybridization oven at $55^{\circ} \mathrm{C}$ for 20 hours. After hybridization, slides were washed with Gene Expression Wash Buffer (Agilent) and scanned with an Agilent Microarray Scanner (G2565BA). Slide images were processed with the Feature Extraction software 10.7 (Agilent) with default settings.

\section{Bioinformatics analysis}

Target genes for each miRNA were manually retrieved from different public databases, including miRecords [28], TarBase [29] and Ingenuity Knowledge Base (Ingenuity Systems, Redwood City, CA, USA). The miRNA target genes included in these databases are all experimentally validated and published in the literature. Gene functional annotations were performed using DAVID Bioinformatics Resources (National Institute of Allergy and Infectious Diseases, NIH) [30] or the IPA software (Ingenuity Systems). Benjamini and Hochberg False Discovery Rate analysis was used for multiple testing correction. The interaction networks were constructed using the Cytoscape platform based on information stored in public databases including BIND, DIP, HPRD, INTACT and BIOGRID [31]. The IA transcriptome data from our previous study were retrieved from GEO database (GSE26969) [15].

\section{Quantitative real-time PCR (qPCR)}

Total RNA of $10 \mathrm{ng}$ was converted to cDNA using miRCURY LNA Universal cDNA Synthesis Kit (Exiqon). The cDNA was diluted 20 times and $4 \mu \mathrm{l}$ of diluted cDNA was added into a $10 \mu \mathrm{l}$ reaction system for qPCR reaction. qPCR was performed with the pre-designed UniRT LNA microRNA primer sets and SYBR Green master mix (all from Exiqon). The catalogue numbers of the primers for miR-99b*, miR-340*, miR-493 and miR-1208 were 204064, 204250, 204557 and 204537 respectively. The sequence for miR-648 was aagugugcagggcacuggu. U6 and RNU5G snRNAs (Exiqon Cat \#203907 and 203908) were used as house-keeping genes. To ensure that the UniRT LNA primer-based PCR reactions had consistent amplification efficiency, we performed characterization experiments by amplifying serial dilutions of synthetic miRNA templates. We confirmed that there was a nice linearity between the log-transformed concentration of input miRNA and the yielding $\mathrm{Ct}$ values $\left(\mathrm{r}^{2}>0.96\right)$. The relative quantification method was used for qPCR data analysis [32]. Principally, $\Delta \mathrm{Ct}$ was calculated as the $\mathrm{Ct}$ value of the test gene minus that of the house-keeping gene. $\Delta \Delta \mathrm{Ct}$ was calculated as the $\Delta \mathrm{Ct}$ value of a given gene in patient subjects minus that in control subjects. The relative gene expression level (fold) was expressed as the calculated value of $2^{-\Delta \Delta \mathrm{Ct}}$.

\section{Statistical analysis}

The raw microarray data were processed and analyzed with the GeneSpring GX software (Agilent). The data were first filtered according to the signal intensities, with genes that were classified as A (absence) in all samples being excluded from further analysis. The Robust Multi-Array Average (RMA) algorithm was used for data normalization, and the Benjamini and Hochberg False Discovery Rate multiple testing correction was used for statistical analysis. Other data were expressed as mean \pm standard error of the mean (SEM). Differences between groups were analyzed with unpaired $t$-test using GraphPad Prism. A value of $P<0.05$ was regarded as statistically significant.

\section{Results}

We profiled global miRNA expression levels in IA tissues and compared with normal blood vessels. Out of the 887 miRNA genes included in the array, 475 miRNAs were detected (not classified as Absence in at least one of the samples tested). Principal component analysis (PCA) of the microarray data showed that IA samples and control samples displayed divergent trends in signal intensity distributions as shown in Figure 2, indicating an altered miRNA expression profile in IAs. Likewise, hierarchical clustering analysis clearly demonstrated that the patterns of global miRNA expression were distinct between IAs and control vessels (with all IA samples and control samples being clustered together respectively) (Figure 2). Specifically, we identified 157 miRNAs that were differentially expressed in IAs $(P<0.05$ and fold change $\geq 2)$, including 72 upregulated and 85 downregulated versus the control vessel (see Addition files 1 \& 2).

Among the changed miRNAs, we observed a number of miRNAs that were primarily involved in functions of vascular endothelial and smooth muscle cells. These included 


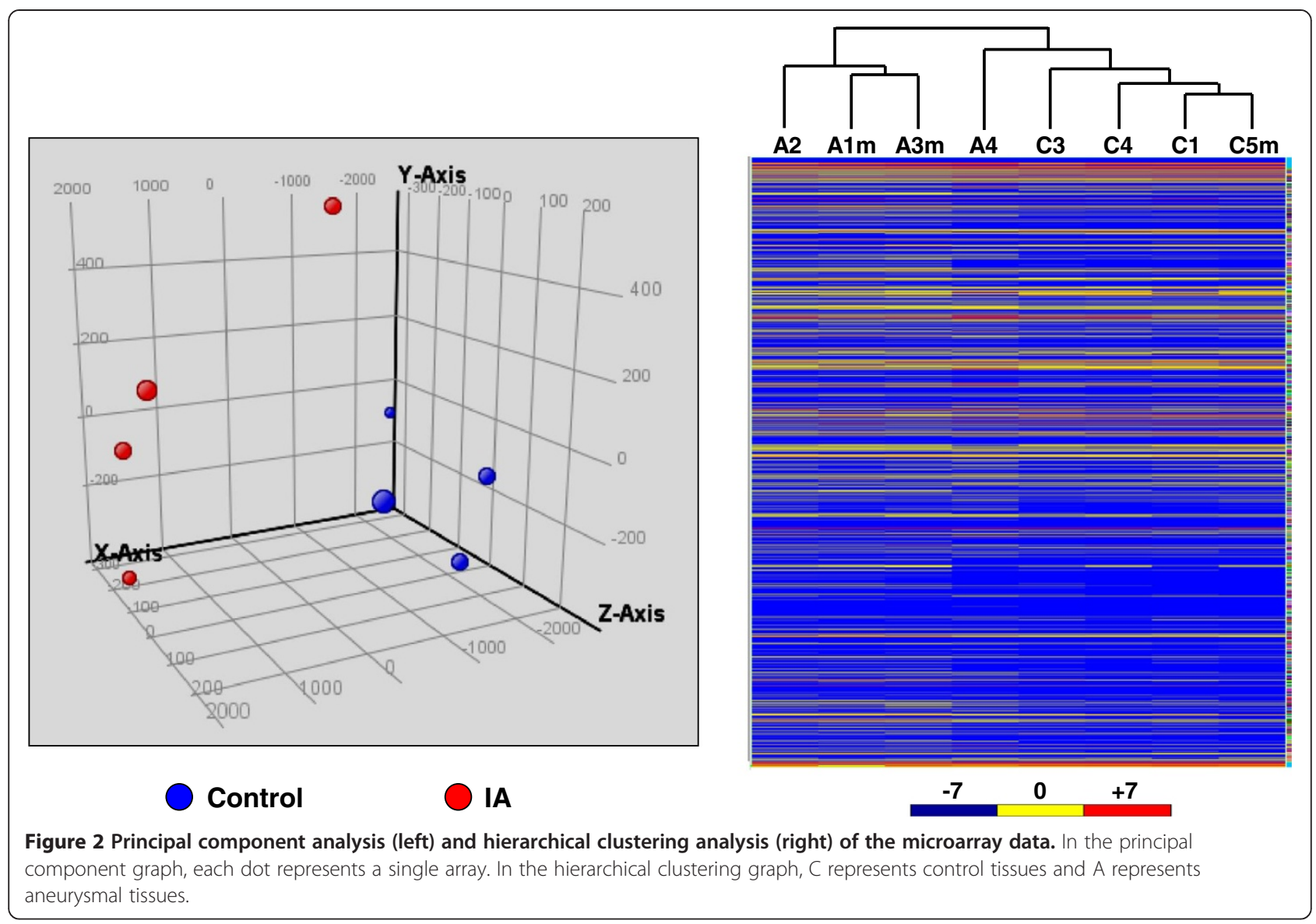

endothelium-enriched miRNAs such as members of the let-7 family (let-7a to let-7g, and let-7i), miR-17, miR-23b, miR-126, hsa-miR-24-1 and miR-222 [25,33]; and vascular smooth muscle-enriched miRNAs such as miR-143 and miR-145 [34,35]. Moreover, the changed miRNAs also contained miR-1, miR-10a, miR-125b, and miR-26a, which were implicated in modulating vascular smooth muscle cell functions such as proliferation, apoptosis and shift of phenotype [34,35]. In contrast, miRNAs involved in monocyte and macrophage functions, such as miR-155, miR-146a, miR-223, and miR-124a, were not significantly changed [25].

To validate the microarray data, we randomly selected five miRNAs, including miR-99b*, miR-340*, miR-493, miR-1208 and miR-648, for qPCR validation (all $P$ values for these miRNAs in the microarray assay being $<0.001$ ). In our preliminary test, however, we found that miR-648 and miR-1208 could not be readily detected by PCR, hence we did not include them in further analysis. For PCR experiments, we used a semi-independent sample including new and the original samples, because of the shortage of clinical IA specimens. Basic clinical parameters of this cohort were: average age $58 \pm 3$ years, $38 \%$ male, $25 \%$ with hypertension history, and $38 \%$ with smoking. We confirmed that miR- 99b* and miR-493 were significantly upregulated in IAs, while miR-340* was downregulated (Figure 3). The trends of change in these miRNAs were consistent with those observed by microarray assays. To exclude the possibility that the selection of house-keeping gene could influence the qPCR results [36], we synthesized a C. elegans miRNA celmiR-39-3p (by TaKaRa, Dalian, China) and used it as a spike-in reference. We determined that neither the U6 gene nor RNU5G gene was significantly different between control and IA samples $(1.2 \pm 0.5$ and $1.3 \pm 0.5$ fold of controls for U6 and RNU5G respectively, all $P>0.05, n=5$ ). In addition, using Cq values of RNU5G as the house-keeping gene did not modify the trend of changes in gene expression as using U6.

To clarify whether and how these changed miRNAs were relevant to the development of IA, we performed bioinformatic data mining by surveying different public databases, and produced a target gene list for all of the differentially expressed miRNAs. Gene functional annotation analysis indicated that multiple biological processes/pathways associated to these miRNAs (and their target genes) were potentially connected to IA formation and/or rupture. These biological processes/pathways include blood vessel development, smooth muscle cell 

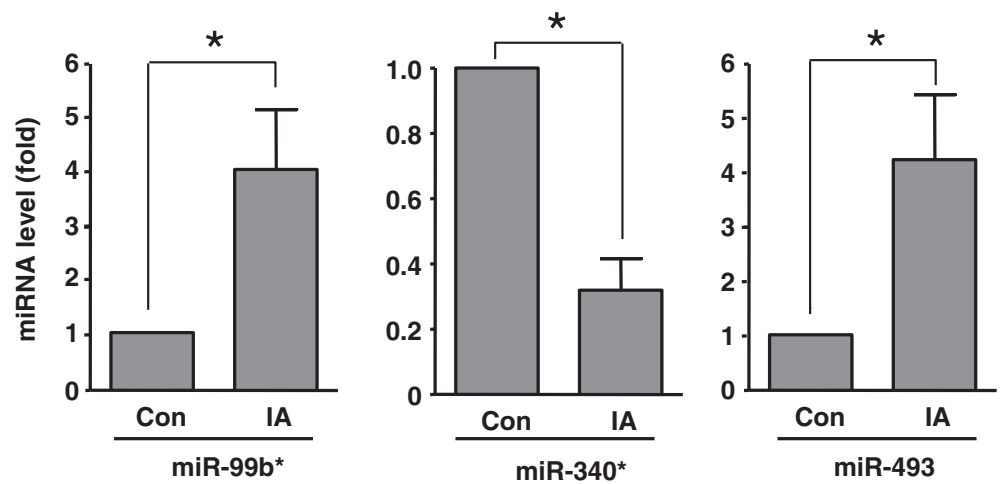

Figure 3 Relative levels of three randomly selected miRNAs in control and aneurysmal tissues as measured by quantitative real-time PCR. ${ }^{*} P<0.05$, unpaired $t$-test, $n=7-9$. Data are expressed as mean \pm SEM.

proliferation, programmed cell death, response to oxidative stress, extracellular matrix organization, transforming growth factor (TGF)- $\beta$ signaling pathway, innate immune response, and leukocyte activation. The miRNA entities under each category and their target genes relevant to IA are summarized in Table 2. Of note, a predicted vascular abnormality that was associated with the changed miRNAs was aortic dissection, another aneurysmal disorder of the artery.

To elucidate functional interrelationships of the miRNA target genes, we performed gene network analysis and created a network map covering a subset of the genes involved (Figure 4). We showed that there were complex functional interactions between the target genes. In particular, we identified several genes that might have the most important functional roles in the network (i.e. those with the highest number of connections with other genes), including p53, Bcl-2, Smad1/3/4, TGF- $\beta$ receptor (TGFBR) 1, MAPK1 (mitogen-activated protein kinase 1, also known as ERK2) and c-Jun (Figure 4).

Bioinformatic analysis revealed that a subset of the potential miRNA target genes belonged to the protein translation machinery, including various eukaryotic translation initiation factors and ribosomal proteins (Table 3). Notably, this finding was highly correlated with our previous transcriptome study with a similar experimental design [15], showing that multiple genes of the ribosomal proteins and translation initiation and elongation factors were significantly downregulated in human intracranial aneurysms (see Table 3).

\section{Discussion}

In this study, we compared miRNA expression profiles in human IAs and normal arterial tissues. We have discovered that there are extensive changes in miRNA expression in IAs, while the biological functions of the majority of these miRNAs remain to be clarified. In a recent study in ruptured IA samples, the authors reported that 18
miRNAs were significantly downregulated in IAs; these miRNAs were associated with functions including proliferation and migration of leukocytes and/or smooth muscle cells [26]. In the present study, we identified 85 downregulated miRNAs in the IA tissue. Notably, 50\% of the downregulated miRNAs reported by the previous study have also been confirmed by our results. However, we also identified 72 miRNAs that were upregulated in IAs, while no miRNA upregulation was detected in the previous study [26]. As suggested, the difference in the number of altered miRNAs detected in the two studies is likely to be due to the small sample size used for microarray analysis [18]. It was noted that only 3 IA specimens were used in the initial microarray discovery stage in the previous study, and this limited biological replication might compromise the rate of positive findings [26].

Genomic annotation analysis has provided some clues on the potential functional connections between the altered miRNAs and IA pathogenesis. Specifically, network analysis revealed that the altered miRNAs were related to several biological processes, including innate immune response, leukocyte activation, extracellular matrix organization, TGF- $\beta$ signaling, smooth muscle cell proliferation, blood vessel development, programmed cell death, and response to oxidative stress. Of note, these biological functions are closely associated with multiple pathological conditions such as inflammation, dysregulation of extracellular matrix, and disrupted blood vessel homeostasis, all of which are closely associated with the development of IA [7,37-40]. Moreover, a subset of the changed miRNAs (e.g. miR-1, miR-125b, miR-222, miR26a, miR-17, miR-126 and miR-23b) have been shown to have important roles in modulating functions of vascular endothelial and smooth muscle cells, and dysregulation of these miRNAs may be associated with various vascular pathologies [33-35]. Also, our results indicate that some of these miRNAs may be involved in modulating the turnover of extracellular matrix. For example, we 


\section{Table 2 Functional classification of changed miRNAs in IA tissues and their target genes}

\begin{tabular}{|c|c|c|}
\hline $\begin{array}{l}\text { Biological processes/ } \\
\text { disorders }\end{array}$ & Changed miRNAs & Corresponding target genes \\
\hline $\begin{array}{l}\text { Programmed cell } \\
\text { death }\end{array}$ & $\begin{array}{l}\text { miR-29b, let-7a, miR-125a-5p, miR-199b-5p, miR-1, miR-30e*, miR-30c, miR-338-3p, miR-133a, miR-101, } \\
\text { miR-26a, miR-362-3p, miR-362-5p, miR-330-3p, miR-296-5p, miR-139-5p, miR-103, miR-218 }\end{array}$ & $\begin{array}{l}\text { TNFRSF10B, TP53, BAK1, CASP6, CASP7, BCL2, CASP3, CASP9, MAP2K7, } \\
\text { PTEN, BAX, AKT2, MAP2K4, MAPK1, MAPK3, PIK3R1, BNIP3L, BECN1 }\end{array}$ \\
\hline $\begin{array}{l}\text { Extracellular matrix } \\
\text { organization }\end{array}$ & miR-1, miR-30e*, miR-30c, miR-133a, let-7a, miR-199b-5p, miR-29b, miR-218 & $\begin{array}{l}\text { SERPINB5, CTGF, COL5A3, COL1A2, COL3A1, COL1A1, TGFBR1, TGFB3, } \\
\text { SMAD3, MMP1, COL15A1, COL4A1, COL4A2, COL5A2, FBN1, SPARC }\end{array}$ \\
\hline $\begin{array}{l}\text { Response to } \\
\text { oxidative stress }\end{array}$ & $\begin{array}{l}\text { miR-133a, miR-30c, miR-199b-5p, miR-125a-5p, miR-1, let-7a, miR-101, miR-338-3p, miR-29b, miR-218, } \\
\text { miR-26a, miR-296-5p, miR-139-5p }\end{array}$ & SIRT1, TXN2, HIF1A, GSS, SOD2, HMOX1, FOXO1, \\
\hline $\begin{array}{l}\text { TGF-beta signaling } \\
\text { pathway }\end{array}$ & $\begin{array}{l}\text { miR-125a-5p, miR-29b, miR-30c, miR-26a, miR-30e*, miR-1, let-7a, miR-218, miR-133a, miR-296-5p, } \\
\text { miR-338-3p, miR-362-3p }\end{array}$ & $\begin{array}{l}\text { ID2, ID1, ID3, ACVR2A, ACVR1, SMAD5, SMAD1, BMPR1B, BMPR2, TGFBR1, } \\
\text { TGFBR2, SMAD4, TGFB3, SMAD3 }\end{array}$ \\
\hline $\begin{array}{l}\text { Smooth muscle cell } \\
\text { proliferation }\end{array}$ & miR-29b, miR-125a-5p, miR-1, let-7a, miR-101, miR-26a, miR-30c & KLF4, ID2, IGFBP3, PPARG, NOTCH3, IGF1, VEGFA, PTK2, JUN \\
\hline Aortic dissection & miR-29b, miR-218, let-7a, miR-26a & COL3A1, COL1A1, TGFBR1, TGFBR2, SMAD3, COL5A2, FBN1 \\
\hline
\end{tabular}

The target genes listed are all experimentally validated and published in the literature. 


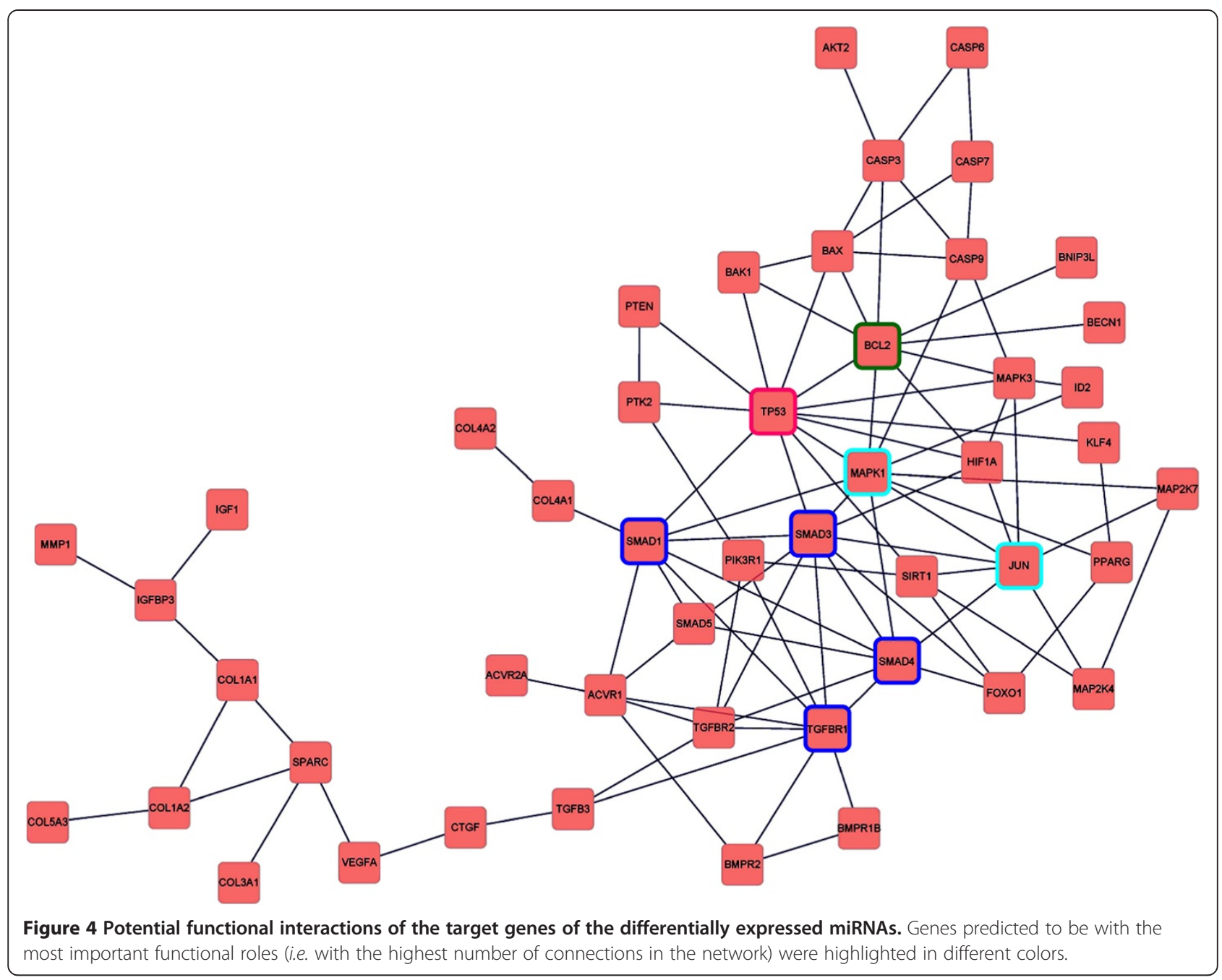

showed that miR-29b was downregulated in IA. In a recent study, Fang et al. demonstrated that one of the direct gene targets of miR-29b was metalloproteinase-2 [41]. It is well documented that aberrant production or activation of metalloproteinases may have a critical role in IA development [42].

A causal role of altered miRNA expression in the pathogenesis of IA remains to be confirmed. In parallel, studies in animal models showed that interventions targeting specific miRNAs might have beneficial effects on the development of AAA [43]. Pahl et al. examined the miRNA expression pattern in human AAA tissues and revealed that miR-133a, miR-133b and miR-331-3p were significantly downregulated in AAAs [24]. Notably, we found that these three miRNAs were also downregulated in IAs, suggesting that they might be involved in some common pathways implicated in arterial aneurysm formation. Dysregulated expression of miR-133a and miR-133b has been found in some types of cancer [44]. Moreover, miR-133a has been shown to have critical roles in modulating cardiac development and maintaining skeletal muscle homeostasis $[45,46]$. Similar to miR-133, miR-331-3p is also involved in regulating growth of certain cancer cells [47]. However, the biological effects of changed expressions of miR-133a/b and miR-331-3p in vascular tissues are currently unclear. In addition, we noted that the majority of changed miRNAs in human AAAs were distinct from those changed in IAs, supporting the argument that AAA and IA might be associated with divergent genetic and/or biochemical mechanisms [48].

An interesting finding was that there was a remarkable correlation between the present genomic miRNA data with our previous IA transcriptome data, showing that a subset of genes related to the protein translation process might be dysregulated in IAs. Indeed, abnormalities of the protein translation machinery underlie a variety of inheritable diseases [49]. Aberrant ribosomal biogenesis has also been linked to cardiovascular pathologies such as myocyte hypertrophy $[50,51]$. In vascular smooth muscle cells, activation of the Akt-mTOR (mammalian target of rapamycin)-p70S6 
Table 3 Genes related to eukaryotic protein translation identified by genomic miRNA and mRNA analyses

\begin{tabular}{|c|c|}
\hline Potential target genes of the altered miRNAs in IA & Downregulated mRNAs in IA* \\
\hline Eukaryotic translation initiation factor 1 (EIF1) & Eukaryotic translation initiation factor 1A, X-linked (EIF1AX) \\
\hline Eukaryotic translation initiation factor $1 \mathrm{~A}, \mathrm{X}$-linked (EIF1AX) & Eukaryotic translation initiation factor 2, subunit 1 (EIF2S1) \\
\hline Eukaryotic translation initiation factor 2, subunit 1 alpha (EIF2S1) & Eukaryotic translation initiation factor 3, subunit 4 (EIF3S4) \\
\hline Eukaryotic translation initiation factor 2, subunit 2 beta (EIF2S2) & Eukaryotic translation initiation factor 3, subunit 7 (EIF3S7) \\
\hline Eukaryotic translation initiation factor 3, subunit H (EIF3H) & Eukaryotic translation initiation factor 3, subunit 9 (EIF3S9) \\
\hline Eukaryotic translation initiation factor 4A1 (EIF4A1) & Eukaryotic translation initiation factor 4B (EIF4B) \\
\hline Eukaryotic translation initiation factor 4 E binding protein 2 (EIF4EBP2) & Eukaryotic translation initiation factor 4E member 3 (EIF4E3) \\
\hline Eukaryotic translation initiation factor 4 gamma, 3 (EIF4G3) & Eukaryotic translation elongation factor 1 delta (EEF1D) \\
\hline Ribosomal protein L32 (RPL32) & Ribosomal protein L10 (RPL10) \\
\hline Ribosomal protein L9 (RPL9) & Ribosomal protein L18 (RPL18) \\
\hline Ribosomal protein S23 (RPS23) & Ribosomal protein L19 (RPL19) \\
\hline Ribosomal protein S4 (RPS4Y1) & Ribosomal protein L3 (RPL3) \\
\hline \multirow[t]{8}{*}{ Ribosomal protein S6 kinase, 90kDa, polypeptide 1 (RPS6KA1) } & Ribosomal protein L35a (RPL35A) \\
\hline & Ribosomal protein L36 (RPL36) \\
\hline & Ribosomal protein L8 (RPL8) \\
\hline & Ribosomal protein S14 (RPS14) \\
\hline & Ribosomal protein S15 (RPS15) \\
\hline & Ribosomal protein S3 (RPS3) \\
\hline & Ribosomal protein S7 (RPS7) \\
\hline & Ribosomal protein 56 kinase, 90kDa, polypeptide 5 (RP \\
\hline
\end{tabular}

*The mRNA data were obtained by reanalysis of our previous data set (GEO accession \#GSE26969).

kinase pathway, the master regulator of eukaryotic protein translation, has profound impacts on the proliferation and differentiation functions [52-54]. Nevertheless, it remains to be clarified whether disruptions of the protein translational process are involved in the pathogenesis of IA.

Functional network analysis on the miRNA target genes suggests that $\mathrm{p} 53, \mathrm{Bcl}-2$, and proteins involved in the TGF- $\beta$ signaling pathway and the MAPK signaling pathway may be important regulators in the process of IA development. Both p53 and Bcl-2-related proteins have critical roles in modulating cell apoptosis and senescence $[55,56]$. Indeed, cell apoptosis appears to be a hallmark of the pathological changes occurring in the aneurysmal vessel wall $[7,57]$. Similarly, previous studies have shown that activation of the MAPK pathway, especially the JNK and p38 kinases, is also increased in IA tissues [58,59]. Given the fundamental roles of JNK and p38 in mediating cell apoptosis and inflammatory responses, and the close relationship between apoptosis/inflammation and IA [7], it is supposed that aberrant activation of the MAPK pathway may have an important role in the pathogenesis of IA [60]. For proteins involved in the TGF- $\beta$ signaling pathway, limited evidence has suggested that the expression levels of TGF- $\beta$ receptors may be changed during IA development [61]. It is known that genetic variations in the TGFBR1 and TGFBR2 genes are associated with an increased risk of AAA; however, there is no evidence that
TGFBR1 or TGFBR2 gene polymorphisms are linked to IA [62]. Hence, an involvement of the TGF- $\beta$ signaling pathway in IAs is still elusive.

A limitation of the present study is the relative small sample number, which is due to the difficulty in collecting suitable clinical IA specimens [63]. The aneurysmal samples included in the present study were obtained with cautions to guarantee that removal of the residual aneurysmal wall after clipping would have no impacts on the outcome of surgical treatment. Likewise, normal cerebral arterial tissues are not readily accessible for many researchers either. Hence, different groups used either superficial temporal arteries or middle meningeal arteries as control in array studies [13,15-17]. In the present study, we could not totally rule out differences in miRNA expressions between the superficial temporal artery and normal cerebral artery. Moreover, the microarray assay cannot provide information on the absolute copy number of a given miRNA, while this disadvantage can be overcome by more advanced technologies such as high-throughput sequencing.

\section{Conclusions}

In this study, we showed that there were extensive changes in miRNA expression in human intracranial aneurysms, and these included several endothelium- and vascular smooth muscle-enriched miRNAs. Our results suggest that 
development of intracranial aneurysms may be associated with disruptions of the normal protein translational process in vascular cells.

\section{Availability of supporting data}

More supporting data for microarray results are included as additional files (Additional file 1: Tables S1 and Additional file 2: Table S2).

\section{Additional files}

Additional file 1: Table S1. MicroRNAs upregulated in human intracranial aneurysm.

Additional file 2: Table S2. MicroRNAs downregulated in human intracranial aneurysm.

\section{Abbreviations}

IA: Intracranial aneurysm; SAH: Subarachnoid hemorrhage; miRNA: microRNA; AAA: Abdominal aortic aneurysm; SEM: Standard error of the mean; PCA: Principal component analysis; MAPK: Mitogen-activated protein kinase; TGF: Transforming growth factor; TGFBR: TGF- $\beta$ receptor.

\section{Competing interests}

The authors declare that they have no competing interest.

\section{Authors' contributions}

DL \& LH participated in data collection; XW performed the PCR experiments; XY \& QZ participated in study design, data analysis and data interpretation; FJ conceived the study, participated in data interpretation, and wrote the manuscript. All authors read and approved the final manuscript.

\section{Acknowledgements}

This work was partially supported by research grants from National 973 Basic Research Program (2010CB732605 for F.J.; 2011 CB503906 for Q.Z.), Science and Technology Department of Jilin Province (No.200705331 for D.L.) Natural Science Foundation of China (81271269 for F.J.; 81220108007 and 81171078 for X.Y.; 81070224 for Q.Z.), and Special Research Project for Capital Health Development (No.2014-1-1071 for X.Y.).

\section{Author details}

'Department of Neurosurgery, China-Japan Union Hospital, Jilin University, Changchun, Jilin Province, China. ${ }^{2}$ Key Laboratory of Cardiovascular Remodeling and Function Research, Qilu Hospital, 107 Wenhuaxi Road, Jinan 250012, Shandong Province, China. ${ }^{3}$ Beijing Neurosurgical Institute, Beijing Tiantan Hospital, Capital Medical University, Beijing, China.

Received: 19 March 2014 Accepted: 22 September 2014

Published online: 10 October 2014

\section{References}

1. Krings T, Mandell DM, Kiehl TR, Geibprasert S, Tymianski M, Alvarez H, ter Brugge KG, Hans FJ: Intracranial aneurysms: from vessel wall pathology to therapeutic approach. Nat Rev Neurol 2011, 7(10):547-559.

2. Brown RD: Unruptured intracranial aneurysms. Semin Neurol 2010, 30(5):537-544.

3. Steiner $T$, Juvela S, Unterberg A, Jung C, Forsting M, Rinkel G: European Stroke Organization guidelines for the management of intracranial aneurysms and subarachnoid haemorrhage. Cerebrovasc Dis 2013, 35(2):93-112.

4. Wardlaw JM, White PM: The detection and management of unruptured intracranial aneurysms. Brain 2000, 123(Pt 2):205-221.

5. Clarke M: Systematic review of reviews of risk factors for intracranial aneurysms. Neuroradiology 2008, 50(8):653-664.

6. Juvela S, Poussa K, Porras M: Factors affecting formation and growth of intracranial aneurysms: a long-term follow-up study. Stroke 2001, 32(2):485-491.
7. Chalouhi N, Ali MS, Jabbour PM, Tjoumakaris SI, Gonzalez LF, Rosenwasser $\mathrm{RH}$, Koch WJ, Dumont AS: Biology of intracranial aneurysms: role of inflammation. J Cereb Blood Flow Metab 2012, 32(9):1659-1676.

8. Sforza DM, Putman CM, Cebral JR: Hemodynamics of Cerebral Aneurysms. Annu Rev Fluid Mech 2009, 41:91-107.

9. Omodaka S, Sugiyama S, Inoue T, Funamoto K, Fujimura M, Shimizu H, Hayase T, Takahashi A, Tominaga T: Local hemodynamics at the rupture point of cerebral aneurysms determined by computational fluid dynamics analysis. Cerebrovasc Dis 2012, 34(2):121-129.

10. Shiue I, Arima H, Hankey GJ, Anderson CS: Dietary intake of key nutrients and subarachnoid hemorrhage: a population-based case-control study in Australasia. Cerebrovasc Dis 2011, 31(5):464-470.

11. Ruigrok YM, Rinkel GJ, Wijmenga C: Genetics of intracranial aneurysms. Lancet Neurol 2005, 4(3):179-189.

12. Caranci F, Briganti F, Cirillo L, Leonardi M, Muto M: Epidemiology and genetics of intracranial aneurysms. Eur J Radiol 2013, 82(10):1598-1605.

13. Pera J, Korostynski M, Krzyszkowski T, Czopek J, Slowik A, Dziedzic T, Piechota M, Stachura K, Moskala M, Przewlocki R, Szczudlik A: Gene expression profiles in human ruptured and unruptured intracranial aneurysms: what is the role of inflammation? Stroke 2010, 41(2):224-231.

14. Krischek B, Kasuya $H$, Tajima A, Akagawa H, Sasaki T, Yoneyama T, Ujiie H, Kubo O, Bonin M, Takakura K, Hori T, Inoue I: Network-based gene expression analysis of intracranial aneurysm tissue reveals role of antigen presenting cells. Neuroscience 2008, 154(4):1398-1407.

15. Li L, Yang $X$, Jiang F, Dusting GJ, Wu Z: Transcriptome-wide characterization of gene expression associated with unruptured intracranial aneurysms. Eur Neurol 2009, 62(6):330-337.

16. Shi C, Awad IA, Jafari N, Lin S, Du P, Hage ZA, Shenkar R, Getch CC, Bredel $\mathrm{M}$, Batjer $\mathrm{HH}$, Bendok BR: Genomics of human intracranial aneurysm wall. Stroke 2009, 40(4):1252-1261.

17. Marchese E, Vignati A, Albanese A, Nucci CG, Sabatino G, Tirpakova B, Lofrese G, Zelano G, Maira G: Comparative evaluation of genome-wide gene expression profiles in ruptured and unruptured human intracranial aneurysms. J Biol Regul Homeost Agents 2010, 24(2):185-195.

18. Roder C, Kasuya H, Harati A, Tatagiba M, Inoue I, Krischek B: Meta-analysis of microarray gene expression studies on intracranial aneurysms. Neuroscience 2012, 201:105-113.

19. Bartel DP: MicroRNAs: genomics, biogenesis, mechanism, and function. Cell 2004, 116(2):281-297.

20. He L, Hannon GJ: MicroRNAs: small RNAs with a big role in gene regulation. Nat Rev Genet 2004, 5(7):522-531.

21. Bonauer A, Boon RA, Dimmeler S: Vascular microRNAs. Curr Drug Targets 2010, 11(8):943-949.

22. McDonald RA, Hata A, MacLean MR, Morrell NW, Baker AH: MicroRNA and vascular remodelling in acute vascular injury and pulmonary vascular remodelling. Cardiovasc Res 2012, 93(4):594-604

23. Wei $Y$, Schober $A$, Weber $C$ : Pathogenic arterial remodeling: the good and bad of microRNAs. Am J Physiol Heart Circ Physiol 2013, 304(8):H1050-H1059.

24. Pahl MC, Derr K, Gäbel G, Hinterseher I, Elmore JR, Schworer CM, Peeler TC, Franklin DP, Gray JL, Carey DJ, Tromp G, Kuivaniemi H: MicroRNA expression signature in human abdominal aortic aneurysms. BMC Med Genomics 2012, 5:25.

25. Kin K, Miyagawa S, Fukushima S, Shirakawa Y, Torikai K, Shimamura K, Daimon T, Kawahara Y, Kuratani T, Sawa Y: Tissue- and plasma-specific MicroRNA signatures for atherosclerotic abdominal aortic aneurysm. J Am Heart Assoc 2012, 1(5):e000745.

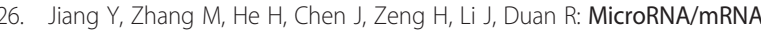
profiling and regulatory network of intracranial aneurysm. BMC Med Genomics 2013, 6(1):36.

27. Guo D, Liu J, Wang W, Hao F, Sun X, Wu X, Bu P, Zhang Y, Liu Y, Liu F, Zhang $Q$, Jiang F: Alteration in Abundance and Compartmentalization of Inflammation-Related miRNAs in Plasma After Intracerebral Hemorrhage. Stroke 2013, 44(6):1739-1742

28. Xiao F, Zuo Z, Cai G, Kang S, Gao X, Li T: miRecords: an integrated resource for microRNA-target interactions. Nucleic Acids Res 2009, 37(Database issue):D105-D110.

29. Vergoulis T, Vlachos IS, Alexiou P, Georgakilas G, Maragkakis M, Reczko M, Gerangelos S, Koziris N, Dalamagas T, Hatzigeorgiou AG: TarBase 6.0: capturing the exponential growth of miRNA targets with experimental support. Nucleic Acids Res 2012, 40(Database issue):D222-D229. 
30. da Huang W, Sherman BT, Lempicki RA: Systematic and integrative analysis of large gene lists using DAVID bioinformatics resources. Nat Protoc 2009, 4(1):44-57.

31. Kohl M, Wiese S, Warscheid B: Cytoscape: software for visualization and analysis of biological networks. Methods Mol Biol 2011, 696:291-303.

32. Livak KJ, Schmittgen TD: Analysis of relative gene expression data using real-time quantitative PCR and the 2(-Delta Delta C(T)) Method. Methods 2001, 25(4):402-408.

33. Santoro MM, Nicoli S: miRNAs in endothelial cell signaling: the endomiRNAs. Exp Cell Res 2013, 319(9):1324-1330.

34. Robinson HC, Baker AH: How do microRNAs affect vascular smooth muscle cell biology? Curr Opin Lipidol 2012, 23(5):405-411.

35. Xie C, Zhang J, Chen YE: MicroRNA and vascular smooth muscle cells. Vitam Horm 2011, 87:321-339.

36. Vandesompele J, De Preter K, Pattyn F, Poppe B, Van Roy N, De Paepe A, Speleman F: Accurate normalization of real-time quantitative RT-PCR data by geometric averaging of multiple internal control genes. Genome Biol 2002, 3(7):RESEARCH0034

37. Penn DL, Witte SR, Komotar RJ, Sander Connolly E Jr: The role of vascular remodeling and inflammation in the pathogenesis of intracranial aneurysms. J Clin Neurosci 2014, 21(1):28-32.

38. Bruno G, Todor R, Lewis I, Chyatte D: Vascular extracellular matrix remodeling in cerebral aneurysms. J Neurosurg 1998, 89(3):431-440.

39. Starke RM, Chalouhi N, Ali MS, Jabbour PM, Tjoumakaris SI, Gonzalez LF, Rosenwasser $\mathrm{RH}$, Koch WJ, Dumont AS: The role of oxidative stress in cerebral aneurysm formation and rupture. Curr Neurovasc Res 2013, 10(3):247-255.

40. Frosen J, Tulamo R, Paetau A, Laaksamo E, Korja M, Laakso A, Niemela M, Hernesniemi J: Saccular intracranial aneurysm: pathology and mechanisms. Acta Neuropathol 2012, 123(6):773-786.

41. Fang JH, Zhou HC, Zeng C, Yang J, Liu Y, Huang X, Zhang JP, Guan XY, Zhuang SM: MicroRNA-29b suppresses tumor angiogenesis, invasion, and metastasis by regulating matrix metalloproteinase 2 expression. Hepatology 2011, 54(5):1729-1740.

42. Aoki T, Kataoka H, Morimoto M, Nozaki K, Hashimoto N: Macrophagederived matrix metalloproteinase- 2 and -9 promote the progression of cerebral aneurysms in rats. Stroke 2007, 38(1):162-169.

43. Maegdefessel L, Azuma J, Toh R, Merk DR, Deng A, Chin JT, Raaz U, Schoelmerich AM, Raiesdana A, Leeper NJ, McConnell MV, Dalman RL, Spin JM, Tsao PS: Inhibition of microRNA-29b reduces murine abdominal aortic aneurysm development. J Clin Invest 2012, 122(2):497-506.

44. Nohata N, Hanazawa T, Enokida H, Seki N: microRNA-1/133a and microRNA-206/133b clusters: dysregulation and functional roles in human cancers. Oncotarget 2012, 3(1):9-21.

45. Liu N, Bezprozvannaya S, Williams AH, Qi X, Richardson JA, Bassel-Duby R, Olson EN: microRNA-133a regulates cardiomyocyte proliferation and suppresses smooth muscle gene expression in the heart. Genes Dev 2008, 22(23):3242-3254.

46. Liu N, Bezprozvannaya S, Shelton JM, Frisard MI, Hulver MW, McMillan RP, Wu Y, Voelker KA, Grange RW, Richardson JA, Bassel-Duby R, Olson EN: Mice lacking microRNA 133a develop dynamin 2-dependent centronuclear myopathy. J Clin Invest 2011, 121(8):3258-3268.

47. Guo X, Guo L, Ji J, Zhang J, Zhang J, Chen X, Cai Q, Li J, Gu Q, Liu B, Zhu Z, Yu Y: miRNA-331-3p directly targets E2F1 and induces growth arrest in human gastric cancer. Biochem Biophys Res Commun 2010, 398(1):1-6.

48. van't Hof FN, Ruigrok YM, Baas AF, Kiemeney LA, Vermeulen SH, Uitterlinden AG, Hofman A, Rivadeneira F, Rinkel GJ, de Bakker PI: Impact of inherited genetic variants associated with lipid profile, hypertension, and coronary artery disease on the risk of intracranial and abdominal aortic aneurysms. Circ Cardiovasc Genet 2013, 6(3):264-270.

49. Scheper GC, van der Knaap MS, Proud CG: Translation matters: protein synthesis defects in inherited disease. Nat Rev Genet 2007, 8(9):711-723.

50. Casad ME, Abraham D, Kim IM, Frangakis S, Dong B, Lin N, Wolf MJ, Rockman $\mathrm{HA}$ : Cardiomyopathy is associated with ribosomal protein gene haploinsufficiency in Drosophila melanogaster. Genetics 2011, 189(3):861-870.

51. Hannan RD, Stefanovsky V, Taylor L, Moss T, Rothblum LI: Overexpression of the transcription factor UBF1 is sufficient to increase ribosomal DNA transcription in neonatal cardiomyocytes: implications for cardiac hypertrophy. Proc Natl Acad Sci U S A 1996, 93(16):8750-8755.

52. Mourani PM, Garl PJ, Wenzlau JM, Carpenter TC, Stenmark KR, Weiser-Evans $M C$ : Unique, highly proliferative growth phenotype expressed by embryonic and neointimal smooth muscle cells is driven by constitutive Akt, mTOR, and p70S6K signaling and is actively repressed by PTEN. Circulation 2004, 109(10):1299-1306.

53. Hegner B, Lange M, Kusch A, Essin K, Sezer O, Schulze-Lohoff E, Luft FC, Gollasch M, Dragun D: mTOR regulates vascular smooth muscle cell differentiation from human bone marrow-derived mesenchymal progenitors. Arterioscler Thromb Vasc Biol 2009, 29(2):232-238.

54. Ma XM, Blenis J: Molecular mechanisms of mTOR-mediated translational control. Nat Rev Mol Cell Biol 2009, 10(5):307-318.

55. Rodier F, Campisi J, Bhaumik D: Two faces of p53: aging and tumor suppression. Nucleic Acids Res 2007, 35(22):7475-7484.

56. Kim R: Unknotting the roles of $\mathrm{BCl}-2$ and $\mathrm{BCl}-\mathrm{xL}$ in cell death. Biochem Biophys Res Commun 2005, 333(2):336-343.

57. Hara A, Yoshimi N, Mori H: Evidence for apoptosis in human intracranial aneurysms. Neurol Res 1998, 20(2):127-130.

58. Takagi Y, Ishikawa M, Nozaki K, Yoshimura S, Hashimoto N: Increased expression of phosphorylated c-Jun amino-terminal kinase and phosphorylated c-Jun in human cerebral aneurysms: role of the c-Jun amino-terminal kinase/c-Jun pathway in apoptosis of vascular walls. Neurosurgery 2002, 51(4):997-1002. discussion 1002-1004.

59. Laaksamo E, Tulamo R, Baumann M, Dashti R, Hernesniemi J, Juvela S, Niemela M, Laakso A: Involvement of mitogen-activated protein kinase signaling in growth and rupture of human intracranial aneurysms. Stroke 2008, 39(3):886-892.

60. Weinsheimer S, Lenk GM, van der Voet M, Land S, Ronkainen A, Alafuzoff I, Kuivaniemi H, Tromp G: Integration of expression profiles and genetic mapping data to identify candidate genes in intracranial aneurysm. Physiol Genomics 2007, 32(1):45-57.

61. Frosen J, Piippo A, Paetau A, Kangasniemi M, Niemela M, Hernesniemi J, Jaaskelainen J: Growth factor receptor expression and remodeling of saccular cerebral artery aneurysm walls: implications for biological therapy preventing rupture. Neurosurgery 2006, 58(3):534-541. discussion 534-541.

62. Ruigrok YM, Baas AF, Medic J, Wijmenga C, Rinkel GJ: The transforming growth factor-beta receptor genes and the risk of intracranial aneurysms. Int J Stroke 2012, 7(8):645-648.

63. Peters DG, Kassam AB, Feingold E, Heidrich-O'Hare E, Yonas H, Ferrell RE, Brufsky A: Molecular anatomy of an intracranial aneurysm: coordinated expression of genes involved in wound healing and tissue remodeling Stroke 2001, 32(4):1036-1042.

doi:10.1186/s12883-014-0188-x

Cite this article as: Liu et al:: Genome-wide microRNA changes in

human intracranial aneurysms. BMC Neurology 2014 14:188.

\section{Submit your next manuscript to BioMed Central and take full advantage of:}

- Convenient online submission

- Thorough peer review

- No space constraints or color figure charges

- Immediate publication on acceptance

- Inclusion in PubMed, CAS, Scopus and Google Scholar

- Research which is freely available for redistribution 